\title{
TWEED'S DIAGNOSTIC FACIAL TRIANGLE FOR NEPALESE ADULTS
}

\author{
Dr Anjana Rajbhandari \\ Associate Professor \& Head; Department of Orthodontics \\ People's Dental College, Kathmandu \\ E-mail: rajbhandari_anjana@yahoo.com
}

\section{ABSTRACT}

A total of 100 lateral cephalograms of the Nepalese adults between the ages of 17 to 30 years were selected from various institutions, communities in Nepal. Cephalograms were traced and measured according to Tweed's descriptions. The results of the study were compared with Caucasians norms established by Tweed. No statistically significant difference between the Nepalese males and females were observed. However, the values were significantly different between Nepalese and Caucasian samples. The mean values for the Nepalese groups were within the range of Tweed's reference values. The results of the study will be useful in the diagnosis and treatment planning of the Nepalese patients.

\section{INTRODUCTION}

The important goals of orthodontic treatment are facial balance and harmony as well as an ideal occlusion. If facial balance does not exist, it should be an overriding priority of orthodontic treatment. Angle's philosophy of retaining all thirty two teeth in dental arch does not fulfill the facial balance and harmony in post treatment cases. On the other hand, Tweed by using cephalometric radiographs; introduced new norms to achieve facial esthetics. His standards led orthodontics into the extraction of first premolars to achieve post treatment stability, better facial esthetics and harmony.

From the time of development of cephalometric radiograph, many pioneer researchers have invented various cephalometric analyses. ${ }^{1-10}$ Thereafter, it has been utilized in various applications, such as; in studying changes during normal growth, ${ }^{11-15}$ determining skeletal and dental changes produced by orthodontic treatments, ${ }^{16-18}$ predicting growth and treatment outcomes ${ }^{19}$, and developing cephalometric norms for different ethnic groups. ${ }^{20-31}$

However, there are very little cephalometric norms available for Nepalese population. In 2005, Bhattarai ${ }^{2}$ conducted a cephalometric study on Nepalese population using Steiner's analysis. Similarly, during the same year Rajbhandari A. ${ }^{33}$ developed cephalometric norms using Downs' analysis. As yet, the Tweed's cephalometric norms has not been developed in Nepalese groups. Thus the aim of this study was to determine normative data representing the Nepalese adults using Tweed's analysis ${ }^{34}$ and to compare the obtained results with those of the Caucasian standards.

\section{MATERIALS AND METHOD}

The materials used in the study consisted of one hundred lateral cephalograms of Nepalese adults with equal gender ratio (50 males and 50 females). A non-probability sampling design was used to describe the craniofacial structures of the Nepalese adults, and to compare them with Caucasian standards.

The inclusion criteria for the samples were Nepalese ethnicity of age ranging between 17-30 years. Angle's class I molar and canine relationships with normal overjet and overbite, having full complement of permanent teeth up to second molar, acceptable facial profile and bilaterally symmetrical face.

The subjects were excluded from the study, when there was proximal caries or restorations, spacing, crowding or rotation; subjects having anterior or posterior cross bite, and missing teeth except third molar.

The standardized lateral cephalometric radiographs were taken from each subject in centric occlusion. The films were processed manually according to the manufacturer's 
instruction. The principal investigator traced and measured all cephalograms over an illuminated view box using the standard technique described Tweed. Each tracing was made on 0.003 matte translucent acetate tracing paper using a 3-H lead pencil.

\section{Following cephalometric landmarks were identified:}

1. Orbitale (Or): Inferior border of the orbital rim

2. Porion (Po): The highest point on the average of the right and left ovoid bony shadow of the external auditory meatus

3. Menton $(\mathrm{Me})$ : The most inferior point on the symphysis

\section{Following cephalometric planes were drawn (Fig 1):}

1. Frankfort horizontal plane: A horizontal plane running through the right and the left cephalometric porion and the left orbitale

2. Mandibular plane: A line tangent to the lower border of the mandible

3. Long axis of lower incisor

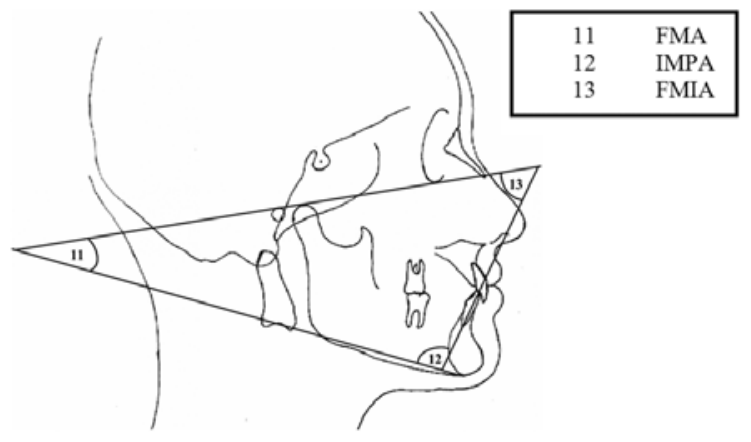

Figure 1. Tweed's Diagnostic Triangle
The angular and linear measurements were made with a transparent metric ruler with protractor. The angular measurements were recorded to the nearest of 0.5 degree and the length was recorded to the nearest of 0.5 millimeter.

To check for the errors in landmark localization and measurement, all lateral cephalograms were retraced by the principal investigator after a period of one month. The difference of more than $1^{\circ}$ or $1 \mathrm{~mm}$ was double-checked and corrected.

The student t- test was used to compare the gender difference within the sample. The t- test was also used to compare the racial differences against the Tweed's standards. The level of significance was set at 0.05 .

\section{RESULTS}

The descriptive statistics including mean, range and standard deviation of Tweed's analysis for combined Nepalese samples are presented in Table 1. The comparison between Nepalese male and female subgroups shows no significant difference in the mean values (Table 2, Graph 1). Table III and Graph 2 show the comparison between the combined Nepalese group and Tweed's Caucasian samples. The Nepalese sample displayed a flatter mandibular plane when compared to Caucasians $(p<0.05)$. The Frankfort-mandibular incisor plane angle, FMIA $(\mathrm{p}<0.001)$ and the Incisor-mandibular plane angle, IMPA $(\mathrm{p}<0.001)$ of the combined Nepalese indicated significantly protrusive lower incisors as compared to Tweed's sample.

Table 1. Descriptive Statistics of Tweed's Analysis of the Combined Nepalese groups

\begin{tabular}{ccccc}
\hline Measurements & Minimum & Maximum & Mean & SD \\
FMA & 14.5 & 32 & 23.2 & 4.2 \\
FMIA & 52 & 74.5 & 62.8 & 4.3 \\
IMPA & 83 & 104 & 94.0 & 4.5 \\
\hline
\end{tabular}

Table 2. Comparison of Tweed's Analysis between Nepalese male and female samples

\begin{tabular}{|c|c|c|c|c|c|c|}
\hline \multirow{2}{*}{ Measurements } & \multicolumn{2}{|c|}{ Male } & \multicolumn{2}{|c|}{ Female } & \multirow{2}{*}{ p-value } & \multirow{2}{*}{ Significance } \\
\hline & Mean & SD & Mean & SD & & \\
\hline FMA & 23.1 & 3.8 & 23.3 & 4.6 & 0.853 & N.S. \\
\hline FMIA & 62.0 & 3.8 & 63.6 & 4.7 & 0.077 & N.S. \\
\hline IMPA & 94.9 & 4.0 & 93.1 & 4.9 & 0.061 & N.S. \\
\hline
\end{tabular}

(N.S. Not significant) 


\begin{tabular}{|c|c|c|c|c|c|c|}
\hline \multirow{2}{*}{ Measurements } & \multicolumn{2}{|c|}{ Nepalese } & \multicolumn{2}{|c|}{ Caucasians } & \multirow{2}{*}{$p$-value } & \multirow{2}{*}{ Significance } \\
\hline & Mean & SD & Mean & SD & & \\
\hline FMA & 23.1 & 4.2 & 24.6 & 5.1 & 0.042 & $*$ \\
\hline FMIA & 62.0 & 4.3 & 68.2 & 5.5 & 0.000 & $* * *$ \\
\hline IMPA & 94.9 & 4.5 & 86.9 & 4.3 & 0.000 & $* * *$ \\
\hline
\end{tabular}

$(* P<0.05, * * * P<0.001)$

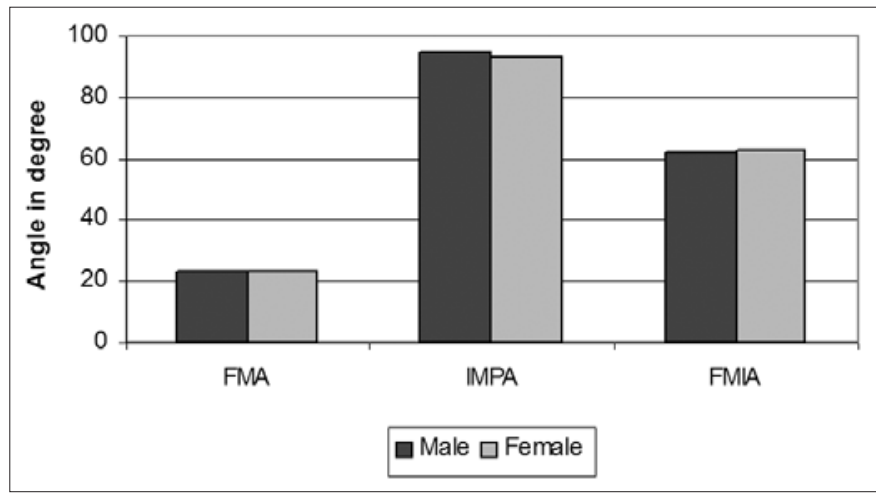

Graph 1. Comparison of Tweed's values between Nepalese male and female samples

\section{DISCUSSION}

Tweed $^{4}$ emphasized the role of Frankfort-mandibular plane angle in orthodontic diagnosis. For better prognosis of the treatment, he favored smaller FMA with the mean value of $25^{\circ}\left( \pm 5^{\circ}\right)$. An FMA of $30^{\circ}$ or more indicate high angle patient, while, an FMA of $20^{\circ}$ or less indicate low angle patient. Tweed suggested that a steeper mandibular plane angle as indicated by Frankfort-mandibular angle greater than $30^{\circ}$, results to a poor prognosis in relation to facial esthetics.

Tweed believed that the incisor mandibular plane angle should range between $85^{\circ}$ and $95^{\circ}$ with the mean value of $90^{\circ}$. For the Frankfort-mandibular incisor angle, he stated the mean value of $65^{\circ}$ is optimum, but the direction of deviation is important. Tweed favored a larger Frankfortmandibular plane angle, towards $70^{\circ}$ rather than toward $60^{\circ}$ for the best esthetic results. In the present study, when the findings of the Nepalese samples were compared with Tweed's sample, the mean values were found to be significantly different (Table 3).

The mean Frankfort-Mandibular Plane Angle obtained for Nepalese $\left(23.1^{\circ}\right)$ males and females $\left(23.3^{\circ}\right)$ indicated no

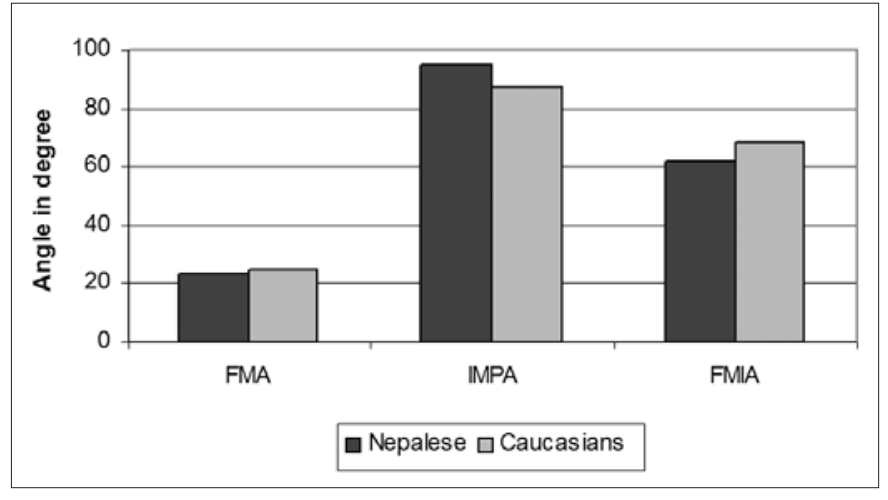

Graph 2. Comparison of Tweed's values between Nepalese and Caucasian samples

significant difference between the gender groups. The mean FMA value for the combined Nepalese group was $23.2^{\circ}$ as compared to Tweed's sample of $24.6^{\circ}$. It is indicative of a flatter mandibular plane for Nepalese group as compared to the Tweed's sample. Although the mean FMA for Nepalese group is not ideal of $25^{\circ}$, it still falls on the low side of the Tweed's preferred range. A small FMA usually denotes good mandibular development specifically in the ramus height. The difference between the two groups could be due to a large variance in both the samples as indicated by the standard deviation. Another explanation is that Tweed selected his samples based mainly on facial esthetics without regard to the role of occlusion.

The mean Incisor Mandibular Plane Angle, IMPA value was greater for Nepalese males $\left(94.9^{\circ}\right)$ as compared to Nepalese females $\left(93.2^{\circ}\right)$. It indicates that the Nepalese males exhibit proclined lower incisors in relation to the mandibular plane. However, the difference of $1.7^{\circ}$ is not statistically significant. Other investigators also noted forward inclination of the mandibular incisors in males as compared to females.

The mean value of the IMPA for the combined Nepalese group (94.9) is greater than the Tweed's sample (86.9), which shows that the Nepalese group exhibited more proclined 
lower incisors than Tweed's group. However, the mean value for the Nepalese group still falls within the Tweed's range of $95^{\circ}$, although it was not upright as suggested by Tweed.

The mean difference of $7.1^{\circ}$ between the Nepalese group and the Tweed's sample is statistically significant at the level of $p<0.001$. This difference can be attributed to Tweed's sample which was based on soft tissue profile rather than dental relationships.

While the FMA angle was found to be lesser in Nepalese group, the IMPA was greater in this group. Tweed's sample exhibited a smaller IMPA angle. These differences indicate that the Nepalese group has a lesser inclination of the mandibular plane to the Frankfort horizontal plane and greater proclination of mandibular incisors. The combination of a flatter mandibular plane with relatively proclined lower incisors may be accompanied by the structural compensations in facial morphology of the Nepalese group.

The mean Frankfort Mandibular Incisor Angle, FMIA for Nepalese males $\left(62.0^{\circ}\right)$ was lesser than the females $\left(63.6^{\circ}\right)$. It reveals that Nepalese females have more upright mandibular incisors than males. However, the difference was not statistically significant. There was a significant difference $(p<0.001)$ between the mean values of FMIA of combined Nepalese $\left(62.8^{\circ}\right)$ and Tweed's sample $\left(68.2^{\circ}\right)$. This difference is attributed to a more proclined mandibular incisors of Nepalese group. It is evident that the mean value for Nepalese group falls short of Tweed's $65^{\circ}$ ideal, but not to a great extent.

The overall comparison discussed above reveal that Nepalese females have a better Tweed pattern than Nepalese males.
The Nepalese face almost falls within Tweed's range of acceptability. However, the reference norms established by Tweed may not be applicable to this group of population because of the large variations in all the measurements.

\section{CONCLUSION}

A cephalometric study of 100 Nepalese adults with equally divided gender ratio of the mean age 20.3 years having excellent occlusion and acceptable facial profile was studied by means of the Tweed's analysis. Measurements were taken for all parameters used in Tweed's analysis. Cephalometric norms was established for Nepalese adults and was compared to Caucasian norms of Tweed's samples. The results of the study revealed significant difference between the Nepalese and Caucasians samples. Thus, to evaluate the Nepalese orthodontic patients, Nepalese standards of Tweed's analysis must be used as a yardstick.

When the comparisons were made within the groups between Nepalese males and females, no statistically significant differences were found in any of the skeletal measurements. The findings of the dental parameters disclosed a significant difference in the lower incisor to occlusal plane angle between the genders.

\section{RECOMMENDATION}

To fully understand the craniofacial morphology of the Nepalese population, the researcher would like to recommend further cephalometric studies on larger sample size and establish different cephalometric standards for the Nepalese children and adolescence groups and evaluation of Cephalometric norms for different major ethnic groups of Nepal. 


\section{REFERENCES}

1. Broadbent, B. H.: A New X-ray Technique and its Application to Orthodontia, Angle Orthod. 2: 45-66, 1931.

2. Downs, W. B.: The role of Cephalometrics in Orthodontic Case Analysis and Diagnosis, Am. J. of Orthod. 38: 162-182, 1952.

3. Tweed, C. H.: The Frankfort-Mandibular Plane Angle in Orthodontic Diagnosis, Treatment Planning and Prognosis, Am. J. Orthod. and Oral Surgery. 32: 175, 1946.

4. Riedel, R. A.: The Relation of Maxillary Structures to Cranium in Malocclusion and in Normal Occlusion, Angle Orthod. 3: $142-145,1952$.

5. Steiner, C.C.: Cephalometrics for You and Me, Am. J. Orthod. 39: 720-755, 1953.

6. Sassouni, V.: A Roentgenographic Cephalometric Analysis of Cephalo-facial Dental Relationships, Angle Orthod. 735-764, 1955.

7. Ricketts, R. M.: Perspectives in the Clinical Applicant of Cephalometrics, Angle Orthod 51: 115-150, 1981.

8. Jacobson, A.: The 'Wits' Appraisal of Jaw Disharmony, Am. J. Orthod. 67: 125-138, 1975.

9. Holdaway, R. A.: A Soft Tissue Ccephalometric Analysis and its Use in Orthodontic Treatment Planning. Part I, Am. J. Orthod. 84: 1-28, 1983.

10. Mc Namara, J. A. Jr.: A Method of Cephalometric Evaluation, Am. J. Orthod. 86: 449-69, 1984.

11. Broadbent, B. H.: The Face of the Normal Child, Angle Orthod. 4: 183-208, 1937.

12. Brodie, A. G.: On the Growth Pattern of Human Head from the Third Month to the Eighth Year of Life, Am. J. Anat. 68:209-261, 1941.

13. Late Growth Changes in the Human Face, Angel Orthod. 28: 146, 1953.

14. Coben, E.: A Serial Cephalometric Roentgenographic Analysis of Cranio-facial Form and Growth, Am. J. Orthod. 41: 407-434, 1955.

15. Bjork A: Variations in the Growth Pattern of the Human Mandible: Longitudinal Radiographic Study by the Implant Method, J Dent Res. 42 : 400-411, 1963.

16. Anderson, J. P., Joondeph, D. R., and Turpin, D. L.: A Cephalometric Study of Profile Changes in Orthodontically Treated Cases Ten Years Out of Retention, Angle Orthod. 43: 324-336, 1973.

17. Baumrind, S., Korn, E. L., Molthen, R., and West, E. E.: Changes in Facial Dimensions Associated with Forces to Retract the Maxilla, Am. J. Orthod. 17-30, 1981.

18. Gebeck, T. M., and Merrifield, L. L.: Orthodontic Diagnosis and Treatment Analysis-Concepts and Values. Part I, Am. J. Orthod. 434-443, 1995.

19. Ricketts, R. M., Bench, R. W., Gugino, C. F., Hilgers, J. J., and Schulhof, R. J.: Bioprogressive Therapy, Denver. Rocky Mountain Orthodontics, 1979.

20. Craven, A. H.: A Radiographic Cephalometric Study of the Central Australian Aboriginal, Angle Orthod. 28: 12-35, 1958.

21. Goldsman, S.: The Variations in Skeletal and Denture Patterns in Excellent Adult Facial Types, Angle Orthod. 29: 63-92, 1959.

22. Altemus, L. A.: A Comparison of Cephalo-facial Relationships, Angel Orthod. 30: 223-240, 1960.

23. Drummond, R. A.: A Determination of Cephalometric Norms for the Negro race, Am. J. Orthod. 54: 670-682, 1968.

24. Nanda, R., and Nanda, R.: Cephalometric Study of the Dento-facial Complex of North Indians, Angel Orthod. 39: 22-28, 1969.

25. Chan, G. K.: A Cephalometric Appraisal of the Chinese (Cantonese), Am. J. Orthod. 61: 279-285, 1972.

26. Gracia, C. J.: Cephalometric Evaluation of Mexican American Using the Downs and Steiner Analyses, Am. J. Orthod. 68: 67-74, 1975.

27. Davoody, V. R., and Sassouni, V.: Dento-facial Pattern Differences between Iranians and American Caucasians, Am. J. Orthod. 73: 667-675, 1978.

28. Hajighdimi, M., Dougherty, H. L., and Garakani, F.: Cephalometric Evaluation of Iranian Children and its Comparison with Tweed and Steiner's Standards, Am. J. Orthod. 1981, 192-197.

29. Park, I., Bowman, D., and Klapper, L.: A Cephalometric Study of Korean Adults, Am. J. Orthod. 96: 54-59, 1989.

30. Kapila, S.: Selected Cephalometric Norms in Kikuyu Children, Angle Orthod. 59: 139-44, 1989.

31. Lim, J. V.: Steiner's Cephalometric Analysis of Filipino Students Aged 16-25, Philippine J Orthod. 1: 23-34, 2000.

32. Bhattarai, P.: Steiner's Cephalometric Analysis of Nepalese Adults Aged 18-30 Years, JNDA. Vol. 7 No. 1, 2005.

33. Rajbhandari A.: A Cephalometric Evaluation of the Nepalese Adults (Aged 17-30 Years) using Downs' Analysis, JNDA. Vol. 7 No. $1,2005$.

34. Tweed, C. H.: The Frankfort-Mandibular Incisor Angle (FMIA) in Orthodontic Diagnosis, Treatment Planning and Prognosis, Angle Orthod. 3: 121-169, 1954. 